\title{
Promotion of C-S bond scission over solid catalytic sulfides by aromatics and nitrogen heterocycles
}

\author{
Edgar M. Morales-Valenciaํㅁㅁ, Omar J. Vargas-Montañez ${ }^{1}$, Pablo A. Monroy-García ${ }^{1}$, \\ Lina G. Avendaño-Barón, Eduard A. Quintero-Quintero, Camila Elder-Bueno ${ }^{1}$, Aidé Y. \\ Santiago-Guerrero ${ }^{1}$, and Víctor G. Baldovino-Medrano ${ }^{1,2, * \text { (D) }}$ \\ ${ }^{1}$ Centro de Investigaciones en Catálisis (@CICATUIS), Parque Tecnológico de Guatiguará (PTG), km 2 \\ vía El Refugio, Universidad Industrial de Santander, Piedecuesta (Santander), 681011, Colombia. \\ ${ }^{2}$ Laboratorio de Ciencia de Superficies (@CSSS_UIS), Parque Tecnológico Guatiguará (PTG), Km. 2 \\ vía El Refugio, Universidad Industrial de Santander, Piedecuesta (Santander), 681011, Colombia.
}

KEYWORDS: Catalytic Sulfides, C-S Bond Scission, Promotion Effect, Aromatics, Nitrogen Heterocycles

\section{ABSTRACT:}

The competitive adsorption of aromatics and nitrogen heterocycles on the active sites of solid catalytic sulfides ( $\mathrm{Ni}(\mathrm{Co})-\mathrm{MoS}_{2}$ dispersed over oxidic carriers) typically causes inhibitory effects during the hydropurification of sulfur heterocycles. Contrary to this typical behavior, we report herein that it is possible to promote the scission of the C-S bond of refractory dibenzothiophene by co-feeding the above compounds during hydropurification over a conventional Ni-MoS$/ \mathrm{Al}_{2} \mathrm{O}_{3}$ catalyst. Particularly, we prove that at temperatures between 240 and $300^{\circ} \mathrm{C}$ and concentrations of dibenzothiophene between 1.0 and 3.7 wt.\%, the desulfurization of dibenzothiophene is promoted by increasing its conversion up to $370 \%$ when either naphthalene, indole, or quinoline are co-fed to the reaction system. The work highlights the following: (i) lower temperatures and higher concentrations of the sulfur heterocycle enhanced the cleavage of the C-S bond from dibenzothiophene; (ii) it is possible to promote hydropurification reactions regardless of the nature of the of co-reactants; namely: a fused aromatic ring -naphthalene-, or a fused nitrogen heterocycle with a lone pair belonging to the pi-system -quinoline- or not -indole-.

The measures that are starting to emerge worldwide for the necessary decarbonization of the transportation sector still leave out important subsectors such as long-haul trucking, aviation, and the cargo industry. Furthermore, in most developing countries these environmental measures do not contemplate replacing fossil fuels for urban transportation in the next few decades. Therefore, producing cleaner fuels while decarbonization takes place remains a critical environmental and societal issue. Within this context, the hydropurification of sulfur heterocycles -hydrodesulfurization- continues driving scientific and industrial innovation. To improve hydropurification, both industry and academia have focused their efforts on the following: i) achieving ultra-deep desulfurization of the fuels to a near zero level of sulfur through the development of highly active catalysts, ${ }^{1}$ and, ii) optimizing hydrogen consumption during hydrotreating due to its impact on the profitability of the process. ${ }^{2,3}$ However, whether it will be feasible to achieve these two challenges simultaneously with the current crude oil quality remains an open question despite the long history of the field.

The presence of nitrogen heterocycles and polyaromatic hydrocarbons on the feedstock of hydrotreating units has been considered one of the main problems to achieve ultra-low sulfur fuels ${ }^{4,5}$ because they can outcompete organosulfur compounds for the active sites of the supported $\mathrm{Ni}(\mathrm{Co})-\mathrm{MoS}_{2}$ catalysts. $^{6-9}$ In this sense, most researches agree that nitrogen heterocycles bind more strongly than aromatics and organosulfur compounds over the catalytic sites hence inhibiting hydropurification. Furthermore, a linear correlation between the proton affinity of different nitrogen heterocycles and the adsorption equilibrium constants has been found (Figure 1S). ${ }^{10,11}$ These findings have reasonably led to a paradigm where nitrogen heterocycles and to some degree aromatic 
hydrocarbons are reaction inhibitors for hydrodesulfurization per se.

Despite the above, a handful of authors reported evidence showing that nitrogen heterocycles may promote hydrodesulfurization. $\mathrm{Nagai}^{12}$ first showed that acridine enhanced the desulfurization of dibenzothiophene with high selectivity to the direct breaking of the C-S bond. Afterwards, LaVopa and Satterfield ${ }^{13}$ reported that quinoline also promoted the desulfurization of dibenzothiophene; particularly, at low temperature. Their finding was confirmed two years ago by Nikul'shina et al. ${ }^{14}$ Finally, Egorova and Prins ${ }^{15}$ showed that either 2-methylpyridine and 2-methylpiperidine can also promote this reaction under specific conditions.

In general, the above studies have the following experimental conditions in common: ${ }^{12-15}$ (i) the reactions were carried out in a continuous flow reactor; (ii) the sulfide based catalysts were promoted by nickel; namely, sulfided $\mathrm{Ni}-\mathrm{MoS}_{2} / \mathrm{Y}$ $\mathrm{Al}_{2} \mathrm{O}_{3}$ and $\mathrm{Ni}-\mathrm{WS}_{2} / \mathrm{Y}-\mathrm{Al}_{2} \mathrm{O}_{3}$; (iii) dibenzothiophene was used as a sulfur heterocycle; and, (iv) all the nitrogen heterocycles had a lone pair belonging to the pi-system hence being Lewis bases. However, these reports have remained a curiosity in the field without further systematic investigations despite the possibility for potential practical applications which would allow optimizing hydrodesulfurization just by modifying the composition of the feed to hydropurification units. Furthermore, as far as we know, there are no studies showing that co-reactants may alter catalytic reactivity beyond classical LangmuirHinshelwood kinetics where they play the role of inhibitors.

Within this context, we sought answering the following questions: 1 ) Is the hydrodesulfurization of dibenzothiophene only promoted by a basic nitrogen heterocycle?; 2) what is the effect of temperature over the promoting effect?; and, 3) what are the effects of the concentration of both the sulfur heterocycle and the promoter fed to the reactor? To respond these questions, we analyzed the effects of naphthalene, as an aromatic compound; and quinoline and indole, as nitrogen compound with basic and non basic character, on the hydrodesulfurization of dibenzothiophene. For this purpose, a series of reaction tests were planned and executed following a factorial $2^{3}$ face-centered cube central composite design experiment for assessing the effects of temperature; 260,280 , and $300^{\circ} \mathrm{C}$, the concentration of dibenzothiophene; 1.0, 2.2, and 3.7 wt.\%; and the concentrations of naphthalene, quinoline, and indole; $0.13,0.28$, and 0.47 wt. $\%$ over the conversion of dibenzothiophene. All tests were done with continuous fixed-bed reactors operated outside mass transport limitations conditions $^{8,16}$ at $p_{\mathrm{H}_{2}}=5 \mathrm{MPa}$ and using samples from a fresh $\mathrm{Ni}-\mathrm{MoS}_{2} / \mathrm{Al}_{2} \mathrm{O}_{3}$ (commercial formulation) catalyst at every independent run.
All tests were made until reaching a steady state where the conversion and selectivity of the dibenzothiophene hydrodesulfurization reaction did not change more than $\pm 2 \%$ with time on stream. An impact factor was defined and calculated to show the degree of promotion or inhibition for the conversion of dibenzothiophene.

$$
\% \lambda_{D B T}=\frac{X_{D B T}^{i}-X_{D B T}}{X_{D B T}} * 100 \%(1)
$$

Where, $X_{D B T}^{i}$ and $X_{D B T}$ represent the conversion of dibenzothiophene in the presence and absence of the co-reactant, respectively. The conversion, yields, and impact factors calculated for each reaction is given in Table S1-S4, of the Supporting Information (Section S2).

Figure 1 shows statistical main effect plots where the average of $\% \lambda_{D B T}$ is presented at each level of the input variables of the experiments, i.e., temperature (Figure 1a), concentration of dibenzothiophene (Figure 1b), and concentration of co-reactant (Figure 1c). In these plots, the magnitude and slope of the lines give a rough idea about the strength and relative significance of the input variable over the impact factor. The higher the slope, the greater the significance of the effect. ${ }^{17}$ According to Figure 1a, the impact factor of indole and naphthalene followed a linear trend with a negative slope. Therefore, the temperature had a significant effect on the promotion effect of these co-reactants over the conversion of naphthalene. At lower temperatures, the promotion due to the presence of indole and naphthalene was higher. On the other hand, the impact factor followed a volcano trend in the presence of quinoline. The effect of the concentration of dibenzothiophene on $\% \lambda_{D B T}$ is depicted in Figurelb. In this case, the overall trends of the promotion effect followed similar curves as before. But, instead of a negative slope for naphthalene and indole, the promotion of the hydrodesulfurization reaction increased with the concentration of dibenzothiophene. Finally, the influence of the concentration of the co-reactants on the impact factor is shown in Figure 1c. In this instance, all compounds had linear effects over the promotion with negative slopes for the concentrations of quinoline and indole and roughly a zero slope for the concentration of naphthalene.

In summary, the statistical analysis of the effects of the input variables of these experiments showed that: (1) the presence of quinoline, indole, and naphthalene can promote the hydrodesulfurization of dibenzothiophene; (2) the degree of promotion follows this trend: indole> naphthalene>quinoline; (3) increasing the reaction temperature had a negative impact on the promotion effect; (4) increasing the concentration of dibenzothiophene positively impacted promotion; and (5) the concentrations 
of quinoline and indole had negative effects over the promotion effect while the effect of the concentration of naphthalene was basically null.

a)

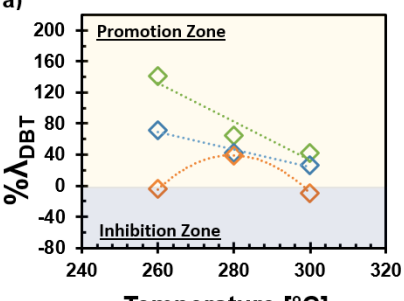

b)
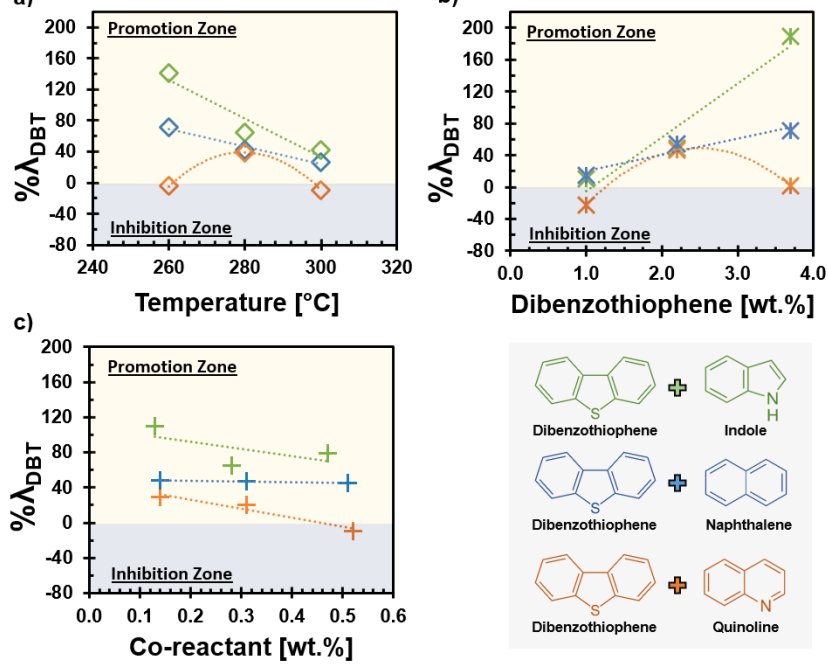

Figure 1. Main effects plots for the impact factor of the conversion of dibenzothiophene: a) temperature, b) concentration of dibenzothiophene, and c) concentration of the coreactant.

On the other hand, it is well known that the hydrodesulfurization of dibenzothiophene undergoes via two parallel pathways: (i) direct desulfurization (DDS) which leads to the formation of biphenyl (BP), and (ii) hydrogenation (HYD) where one of the benzene rings of dibenzothiophene is first hydrogenated to tetrahydro-dibenzothiophene (THDBT) and then to hexa-hydro-dibenzothiophene (HHDBT), followed by the scission of the C-S-C bond to yield cyclohexylbenzene $(\mathrm{CHB}){ }^{8}$ In this sense, it is necessary to analyze how the above described effects affected both pathways.

Figure 2 shows a parity diagram for the yields of cyclohexylbenzene and biphenyl during the hydrodesulfurization of dibenzothiophene in the absence and presence of each co-reactant. In general, quinoline, indole, and naphthalene promoted the yield to biphenyl, i.e., the direct scission of C-S-C bond, Figure 2a. Also, naphthalene was able to promote the production of cyclohexylbenzene, Figure $\mathbf{2 b}$, but both nitrogen heterocycles inhibited the yield to cyclohexylbenzene. The latter is the typical finding in the literature. ${ }^{18,19}$
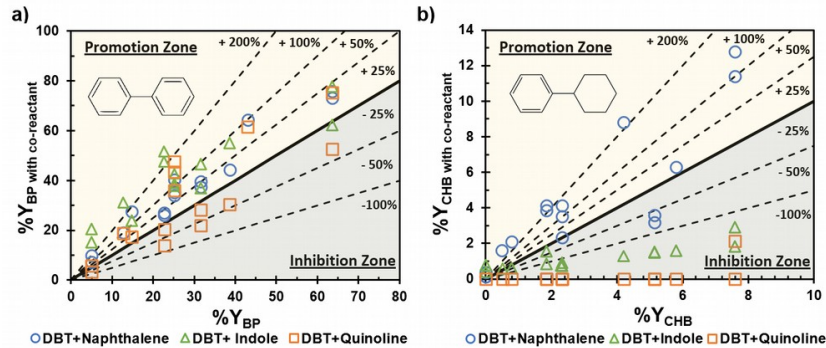

Figure 2. Parity diagram for the yields of a) cyclohexylbenzene (CHB) and b) biphenyl (BP) in the hydrodesulfurization of dibenzothiophene in the absence and presence of the co-reactant.

The ensemble of the presented results hint that the origin of the promotion effect of the studied molecules may be related to the surface coverage of the different reactants (high concentrations of dibenzothiophene and low reaction temperatures) and their influence on the catalytic sites where direct desulfurization takes place. Despite the fact that this work cannot conclude nothing on the origin of the demonstrated promotion effects, we advance two non-mutually excluding hypotheses about it. The first one is that aromatics and nitrogen heterocyclic compounds promote hydrodesulfurization via direct desulfurization because their adsorption lowers the strength of the neighboring metal-sulfur bond (S-H group binding energy) hence easing the formation of more active sites such as sulfur vacancies. This hypothesis could be supported by studies showing the existence of a correlation between the $\mathrm{SH}$ group binding energy and the activity in hydrodesulfurization reactions. ${ }^{20-22}$ Indeed, Moses et al. ${ }^{22}$ proposed the $\mathrm{SH}$ binding energy as a descriptor for the rate of hydrodesulfurization. They mentioned that an intermediate strength of the $\mathrm{SH}$ binding would be at optimum range for the hydrodesulfurization activity according to the Sabatier principle. To the left of the maximum the $\mathrm{SH}$ binding energy becomes weaker and on the right side increases the strength of $\mathrm{SH}$ binding. From our results, it was evidenced that indole that has an intermediate proton affinity $(933.4 \mathrm{~kJ}$ $\left.\mathrm{mol}^{-1}\right)$ between naphthalene $\left(836.0 \mathrm{~kJ} \mathrm{~mol}^{-1}\right)$ and quinoline $\left(953.2 \mathrm{~kJ} \mathrm{~mol}^{-1}\right)$ led to a stronger promotion effect. In line with this hypothesis, quinoline showed a volcano-type plot for the promotion of dibenzothiophene, probably because of the tendency of the nitrogen heteroatom to donate electrons was more sensible to the effect of the temperature (Figure 1a) and to the concentration of dibenzothiophene (Figure1b). In this sense, the difference in the adsorption structures and the strength of the adsorption of the co-reactants may affect the degree of influence on the $\mathrm{SH}$ binding energy, and, therefore, the promotion of the DDS pathway. 
The second hypothesis is that the hydrogenation-dehydrogenation equilibrium established in the first step of the hydrotreating reaction sequence for the naphthalene ${ }^{8,23}$, indole ${ }^{24}$, and quinoline ${ }^{25,26}$ could supply additional surface hydrogen for the C-S bond scission reaction. The reactions networks of the hydrogenations of quinoline, indole, and naphthalene are presented in the Supporting Information (Section S3). According to $\mathrm{Li}$ and Iglesia ${ }^{27}$, propane dehydrogenation can promote the hydrodesulfurization of thiophene because of this. Also, in recent years a large number of articles dealing with the feasibility of using organic compounds as hydrogen carriers have been published. ${ }^{28-30}$ Several authors have found that the dehydrogenation of compounds containing a heteroatom within a five membered ring is favored as compared to the one with a heteroatom within a six member ring. ${ }^{31,32}$ This agrees with our results in the sense that indole had a stronger promotion effect than quinoline and naphthalene.

As mentioned earlier, the two hypotheses proposed to explain the promotion of hydrodesulfurization by naphthalene, quinoline, and indole are not mutually excluding. Both the adsorption of the aromatic and nitrogen compounds and the release of hydrogen by dehydrogenation may modify the binding energy of the surface $\mathrm{SH}$ groups and promote the formation of more sulfur vacancies. In the case of the supply of surface hydrogen by dehydrogenation reactions, these surface species could react with an $\mathrm{SH}$ group to form $\mathrm{H}_{2} \mathrm{~S}$ hence leaving behind a new sulfur vacancy available for desulfurization.

As a conclusion, the response to the three questions postulated for this work are: 1) The C-S bond scission necessary for the hydrodesulfurization of dibenzothiophene over solid catalytic sulfides is promoted by both basic (quinoline) and non-basic (indole) nitrogen heterocycles and by aromatics (naphthalene). 2) Lower temperatures strengthen the promotion effects of indole and naphthalene, while it has a volcano effect over the promotion effect of quinoline. 3) A larger concentration of dibenzothiophene leads to stronger promotion effects of indole and naphthalene while over quinoline promotion followed a volcano trend.

\section{ASSOCIATED CONTENT \\ Supporting Information}

The supporting information is available free of charge via the Internet at http://pubs.acs.org.

Correlation between adsorption equilibrium constants and proton affinity, all data of the reactions of hydrodesulfurization, and reaction networks of co-reactants.

\section{AUTHOR INFORMATION}

\section{Corresponding Author}

*Email: vicbaldo@uis.edu.co, Twitter: @vigabalme, Tel. +54 6344000 ext. 1485 .

http://orcid.org/0000-0003-3227-0251.

\section{Author Contributions}

E.M.M.-V co-directed the project and wrote the original draft of the paper. O.J.V.-M, P.M, C.E, and Y.S made the experiments. V.G.B.-M directed the project and revised and contributed to writing the manuscript. All authors have approved the final version of the manuscript.

\section{Funding Sources}

This work was funded by Agencia Nacional de Hidrocarburos -ANH- and Minciencias, Colombia, within the frame of the Project 110284769842: "Desarrollo de una estrategia catalítica para un proceso de in-situ upgrading acoplado con procesos de combustión in-situ para optimizar la producción y mejorar la calidad de crudos pesados y extrapesados colombianos por reacciones de transferencia de hidrógeno".

ACKNOWLEDGMENT

\section{REFERENCES}

(1) Tanimu, A.; Alhooshani, K. Advanced Hydrodesulfurization Catalysts: A Review of Design and Synthesis. Energy \& Fuels 2019, 33 (4), 28102838.

(2) A. Alabdullah, M.; Rodriguez Gomez, A.; Vittenet, J.; Bendjeriou-Sedjerari, A.; Xu, W.; A. Abba, I.; Gascon, J. A Viewpoint on the Refinery of the Future: Catalyst and Process Challenges. ACS Catal. 2020, 10 (15), 8131-8140.

(3) Weng, X.; Cao, L.; Zhang, G.; Chen, F.; Zhao, L.; Zhang, Y.; Gao, J.; Xu, C. Ultradeep Hydrodesulfurization of Diesel: Mechanisms, Catalyst Design Strategies, and Challenges. Ind. Eng. Chem. Res. 2020, 59 (49), 21261-21274.

(4) Wu, G.; Yin, Y.; Chen, W.; Xin, F.; Lu, Y.; Qin, K.; Zhang, L.; Song, Y.; Li, M. Catalytic Kinetics for Ultra-Deep Hydrodesulfurization of Diesel. Chem. Eng. Sci. 2020, 214, 115446.

(5) Tao, X.; Zhou, Y.; Wei, Q.; Ding, S.; Zhou, W.; Liu, T.; Li, X. Inhibiting Effects of Nitrogen Compounds on Deep Hydrodesulfurization of Straight-Run Gas Oil over a NiW/Al2O3 Catalyst. Fuel 2017, 188, 401-407.

(6) Rangarajan, S.; Mavrikakis, M. On the Preferred Active Sites of Promoted MoS2 for Hydrodesulfurization with Minimal Organonitrogen Inhibition. ACS Catal. 2017, 7 (1), 501-509.

(7) Liu, X.; Fan, X.; Wang, L.; Sun, J.; Wei, Q.; Zhou, Y.; Huang, W. Competitive Adsorption between Sulfurand Nitrogen-Containing Compounds over NiMoS Nanocluster: The Correlations of Electronegativity, Morphology and Molecular Orbital with Adsorption Strength. Chem. Eng. Sci. 2021, 231, 116313.

Morales-Valencia, E. M.; Castillo-Araiza, C. O.; Giraldo, S. A.; Baldovino-Medrano, V. G. Kinetic Assessment of the Simultaneous Hydrodesulfurization of Dibenzothiophene and the 
Hydrogenation of Diverse Polyaromatic Structures. ACS Catal. 2018, 8 (5).

(9) Rana, M. S.; Al-Barood, A.; Brouresli, R.; Al-Hendi, A. W.; Mustafa, N. Effect of Organic Nitrogen Compounds on Deep Hydrodesulfurization of Middle Distillate. Fuel Process. Technol. 2018, 177, 170-178.

(10) Nagai, M.; Sato, T.; Aiba, A. Poisoning Effect of Nitrogen Compounds on Dibenzothiophene Hydrodesulfurization on Sulfided NiMo/Al2O3 Catalysts and Relation to Gas-Phase Basicity. J. Catal. 1986, 97 (1), 52-58.

(11) LaVopa, V.; Satterfield, C. N. Poisoning of Thiophene Hydrodesulfurization by Nitrogen Compounds. J. Catal. 1988, 110 (2), 375-387.

(12) Nagai, M. High Activity and Selectivity of a "Poisoned" NiMo/Al2O3 Catalyst for a Desulfurization Reaction. Ind. Eng. Chem. Prod. Res. Dev. 1985, 24 (3), 489-491.

(13) LaVopa, V.; Satterfield, C. N. Response of Dibenzothiophene Hydrodesulfurization to Presence of Nitrogen Compounds. Chem. Eng. Commun. 1988, 70 (1), 171-176.

(14) Nikul'shina, M. S.; Mozhaev, A. V.; Lancelot, C.; Blanchard, P.; Lamonier, C.; Nikul'shin, P. A. Effect of Quinoline on Hydrodesulfurization and Hydrogenation on $\mathrm{Bi}$ - and Trimetallic NiMo(W)/Al 2 O 3 Hydrotreating Catalysts. Russ. J. Appl. Chem. 2019, 92 (1), 105-112.

(15) Egorova, M.; Prins, R. Promotion Effect of 2Methylpiperidine on the Direct Desulfurization of Dibenzothiophene over NiMo/Y-Al2O3. Catal. Letters 2004, 92 (3), 87-91.

(16) Celis-Cornejo, C. M.; Pérez-Martínez, D. J.; OrregoRuiz, J. A.; Baldovino-Medrano, V. G. Identification of Refractory Weakly Basic Nitrogen Compounds in a Deeply Hydrotreated Vacuum Gas Oil and Assessment of the Effect of Some Representative Species over the Performance of a Ni-MoS2/YZeolite-Alumina Catalyst in Phenanthrene Hydrocracking. Energy and Fuels 2018, 32 (8), 8715-8726.

(17) Antony, J. A Systematic Methodology for Design of Experiments. In Design of Experiments for Engineers and Scientists; Elsevier, 2014; pp 33-50.

(18) Salazar, N.; Schmidt, S. B.; Lauritsen, J. V. Adsorption of Nitrogenous Inhibitor Molecules on MoS2 and CoMoS Hydrodesulfurization Catalysts Particles Investigated by Scanning Tunneling Microscopy. J. Catal. 2019, 370, 232-240.

(19) Rangarajan, S.; Mavrikakis, M. DFT Insights into the Competitive Adsorption of Sulfur- and NitrogenContaining Compounds and Hydrocarbons on CoPromoted Molybdenum Sulfide Catalysts. ACS Catal. 2016, 6 (5), 2904-2917.

(20) Permyakov, E. A.; Solkan, V. N.; Kogan, V. M. Role of $\mathrm{SH}$ Groups and Chemisorbed Hydrogen in the Formation of Sulfur Vacancies on an Edge of a Molybdenum Disulfide Crystallite. Kinet. Catal. 2015, 56 (2), 147-157.

(21) Sharifvaghefi, S.; Yang, B.; Zheng, Y. New Insights on the Role of $\mathrm{H} 2 \mathrm{~S}$ and Sulfur Vacancies on Dibenzothiophene Hydrodesulfurization over MoS2 Edges. Appl. Catal. A Gen. 2018, 566, 164-173.

(22) Moses, P. G.; Grabow, L. C.; Fernandez, E. M.; Hinnemann, B.; Topsøe, H.; Knudsen, K. G.; Nørskov, J. K. Trends in Hydrodesulfurization Catalysis Based on Realistic Surface Models. Catal. Letters 2014, 144 (8), 1425-1432.

(23) Stanislaus, A.; Cooper, B. H. Aromatic Hydrogenation Catalysis: A Review. Catal. Rev. 1994, 36 (1), 75-123.

(24) Nguyen, M.-T.; Pirngruber, G. D.; Chainet, F.; Tayakout-Fayolle, M.; Geantet, C. Indole Hydrodenitrogenation over Alumina and SilicaAlumina-Supported Sulfide Catalysts-Comparison with Quinoline. Ind. Eng. Chem. Res. 2017, 56 (39), 11088-11099.

(25) Nguyen, M.-T.; Tayakout-Fayolle, M.; Pirngruber, G. D.; Chainet, F.; Geantet, C. Kinetic Modeling of Quinoline Hydrodenitrogenation over a NiMo(P)/Al2O3 Catalyst in a Batch Reactor. Ind. Eng. Chem. Res. 2015, 54 (38), 9278-9288.

(26) Prins, R. Catalytic Hydrodenitrogenation. Adv. Catal. 2001, 46, 399-464.

(27) Li, W.; Yu, S. Y.; Iglesia, E. Deuterium Isotopic Tracer Studies of Thiophene Desulfurization Pathways Using Propane or Dihydrogen as CoReactants. J. Catal. 2002, 207 (1), 31-36.

(28) Niermann, M.; Timmerberg, S.; Drünert, S.; Kaltschmitt, M. Liquid Organic Hydrogen Carriers and Alternatives for International Transport of Renewable Hydrogen. Renew. Sustain. Energy Rev. 2021, 135, 110171.

(29) Zou, Y. Q.; von Wolff, N.; Anaby, A.; Xie, Y.; Milstein, D. Ethylene Glycol as an Efficient and Reversible Liquid-Organic Hydrogen Carrier. Nat. Catal. 2019, 2 (5), 415-422.

(30) M. Modisha, P.; N. M. Ouma, C.; Garidzirai, R.; Wasserscheid, P.; Bessarabov, D. The Prospect of Hydrogen Storage Using Liquid Organic Hydrogen Carriers. Energy \&amp; Fuels 2019, 33 (4), 27782796.

(31) Bourane, A.; Elanany, M.; Pham, T. V.; Katikaneni, S. P. An Overview of Organic Liquid Phase Hydrogen Carriers. International Journal of Hydrogen Energy. December 2016, pp 2307523091.

(32) Guido P. Pez; Alan C. Cooper; Hansong Cheng. Hydrogen Storage by Reversible Hydrogenation of Pi-Conjugated Substrates. US7101530B2. 